\title{
A Promising Material for Non-linear Optics: Observation of Second Harmonic Generation from 4-[N-(4-Carboxypentyl)- $\mathrm{N}$-methylamino]-4'-nitrostilbene-coated Substrates
}

\author{
John W. Barton, a Michael Buhaenko, ${ }^{a}$ Brian Moyle,, and Norman M. Ratcliffe ${ }^{*_{c}}$ \\ a School of Chemistry, University of Bristol, Cantocks Close, Bristol BS8 1TS, U.K. \\ b School of Chemistry and Molecular Sciences, University of Sussex, Falmer, Brighton BN1 9OJ, U.K. \\ c British Aerospace, Sowerby Research Centre, P.O. Box 5, Filton BS12 7OW, U.K.
}

Glass coated with a nitro amino stilbene carboxylic acid using the Langmuir-Blodgett technique gave a non-centrosymmetric material exhibiting second harmonic generation, 1.06 to $0.53 \mu \mathrm{m}$.

There is much interest in materials with a large second-order non-linear susceptibility.1.2 Work has been recently published ${ }^{3}$ on the synthesis and non-linear optical properties of nitro amino stilbenes. We report here some of our work on similar type molecules which were tailor made for incorporation into Langmuir-Blodgett multilayers.

Materials with significant second-order non-linear optical properties are composed of molecules which have a large difference in dipole moment between the ground and the excited state, and which are aligned producing a net dipole in the bulk material. ${ }^{4.5}$ The nitro amino stilbene group has been calculated to have a particularly high second-order non-linear coefficient $\left(\beta c a .450 \times 10^{-30}\right.$ e.s.u. for 4 -nitro-4'-dimethylaminostilbene). ${ }^{6}$ The structural features that lead to a large $\beta$ value also lead to a large ground state dipole moment, resulting in an energetically unfavourable interaction between adjacent molecules which may favour a centrosymmetric crystal structure. This is presumably the reason for crystals of the nitro amino stilbenes described here and elsewhere, ${ }^{6}$ e.g. 4-nitro-4'-dimethylamino stilbene, showing no second harmonic generation (S.H.G.); however, weak S.H.G. has recently been observed from a crystalline $N$-( $p$-heptyloxy)benzyl derivative. ${ }^{3}$

The Langmuir-Blodgett (L.B.) method is capable of producing non-centrosymmetric structures exhibiting S.H.G. ${ }^{7.8}$ and L.B. monolayers of nitro amino stilbene derivatives have shown S.H.G. ${ }^{9}{ }^{10}$ A glass substrate pulled through the monolayer of (4) on water caused a transfer of material. Multiple dippings resulted in suspected Z-type ${ }^{11}$ deposition with the molecules orientated in a head-to-tail, head-to-tail fashion, where the carboxylic acid grouping is the head. A long alkyl chain (for monolayer stability) is a common feature of molecules incorporated into multilayer L.B. noncentrosymmetric structures ${ }^{7-10}$ and this lowers the number of active chromophores per unit volume. Compound (4) can form a stable monolayer on water without this undesirable feature.

The Wadsworth-Emmons reaction ${ }^{12}$ was utilised for the stilbene syntheses. Reaction of $p$-nitrobenzyl bromide with triethyl phosphite gave $(\mathbf{A})$, Scheme $1\left(120^{\circ} \mathrm{C}, 12 \mathrm{~h}\right.$, vacuum distillation, ca. $49 \%$ yield). Ylide formation by sodium hydride/diglyme (room temp.) and then addition of the appropriate aldehyde (room temp., ca. $30 \mathrm{~min}$ ), followed by work-up and flash chromatography (silica gel) gave the amino stilbenes as deep red crystals $(45 \%)$ and the oxy-stilbenes as yellow crystals $(40 \%)$, Scheme 1 . Yields were lower if tetrahydrofuran (THF) was used as solvent for the Wittig reaction.

The aldehydes were readily prepared by $N$-alkylation of $N$-methylaniline with the appropriate alkyl bromide [hexamethylphosphoric triamide (HMPA), $\mathrm{NaHCO}_{3}, 90^{\circ} \mathrm{C}$, yields $60-80 \%$ ] followed by the Vilsmeir-Haack ${ }^{11}$ reaction $\left[110^{\circ} \mathrm{C}\right.$, $2 \mathrm{~h}$, dimethylformamide (DMF), $\mathrm{POCl}_{3}, \mathrm{ca} .60 \%$ yield].

The facile alkylation of $p$-hydroxybenzaldehyde was undertaken in $\mathrm{DMF} / \mathrm{NaHCO}_{3}$, ca. $80^{\circ} \mathrm{C}$, with the appropriate bromo analogue. Esters (3) and (5) were converted into their 
<smiles>Cc1ccc([N+](=O)[O-])cc1</smiles><smiles>CC#CC</smiles>

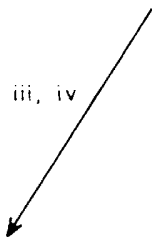<smiles>[R]Oc1ccc(/C=C/c2ccc([N+](=O)[O-])cc2)cc1</smiles>

(5) $\mathrm{R}^{2}=\left(\mathrm{CH}_{2}\right)_{3} \mathrm{CO}_{2} \mathrm{Me}$

(6) $\mathrm{R}^{2}=\left(\mathrm{CH}_{2}\right)_{3} \mathrm{CO}_{2} \mathrm{H}$

(7) $\mathrm{R}^{2}=\left(\mathrm{CH}_{2}\right)_{17} \mathrm{Me}$<smiles>CCOP(=O)(Cc1ccc([N+](=O)[O-])cc1)OCC</smiles>

(A)
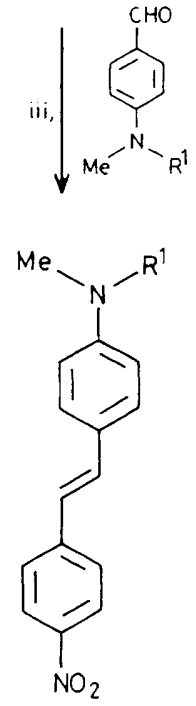

(1) $\mathrm{R}^{1}=\left(\mathrm{CH}_{2}\right)_{17} \mathrm{Me}$

(2) $\mathrm{R}^{1}=\left(\mathrm{CH}_{2}\right)_{8} \mathrm{Me}$

(3) $\mathrm{R}^{\prime}=\left(\mathrm{CH}_{2}\right)_{4} \mathrm{CO}_{2} \mathrm{Me}$

(4) $\mathrm{R}^{1}=\left(\mathrm{CH}_{2}\right)_{4} \mathrm{CO}_{2} \mathrm{H}$

Scheme 1. Reagents and conditions: i, $N$-bromosuccinimide (NBS), $\mathrm{CCl}_{4}, h v$; ii, $\mathrm{P}(\mathrm{OEt})_{3}$, heat; iii, $\mathrm{NaH}$, diglyme, room temp.; iv, aldehyde, room temp.

respective acids (4) and (6) by alkaline hydrolysis (90\% $\mathrm{MeOH}, 10 \%, \mathrm{H}_{2} \mathrm{O}$, reflux, excess $\mathrm{NaOH}$ ) followed by acidification $(2 \mathrm{M} \mathrm{HCl})$ work-up and recrystallisation from methanol. Compound (4) was obtained in high yield ( $c a$. $90 \%$ ), while compound (6) was obtained in surprisingly low yield. All new compounds had spectral properties in agreement with their structure.

The compounds (1)-(7) were dissolved in chloroform (typically $10 \mathrm{mg} / 25 \mathrm{ml}$ ) and carefully applied to the water surface ( $\mathrm{pH} 3.7)$ in a Langmuir-Blodgett trough. Only (3) and (4) formed monolayers, the surface pressure/area characteristics showing an acceptable area/molecule of $c a .21 .5 \AA^{2}$ (the area derived from space-filling models is $c a .17 \AA^{2}$ ). Deposition of (4) was obtained on hydrophilic and hydrophobic $\left(\mathrm{SiCl}_{2} \mathrm{Me}_{2}\right.$, methylene chloride treatment) Chance Propper microscope slides; no transfer of material was obtained for (3). Deposition occurred on withdrawal only and the quantity of monolayer transferred was equivalent to $c a$. $60 \%$ substrate coverage for each dip.

Dipping (20 times) gave a clearly visible red coating which for the hydrophilic microscope slide exhibited strong S.H.G. with a $1.06 \mu \mathrm{m} \mathrm{Nd} / \mathrm{YAG}$ laser. The S.H.G. was obtained in areas ranging from $c a .1$ to $c a .50 \mathrm{~mm}^{2}$ and compared to a standard of potassium dihydrogen phosphate (KDP) powder

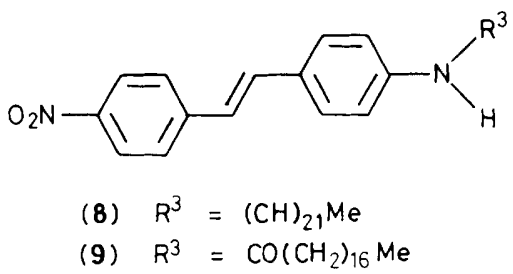

( $450 \mu \mathrm{m}$ thick) showed relative outputs varying between 0.06 and 1.1. The S.H.G. effect was patchy reflecting the incomplete deposition. Most of the signal was found on transmission. Space filling molecules give the molecular length as ca. $19 \AA$; hence a multilayer 20 molecules thick with a relative S.H.G. of 0.3 (which corresponded to two areas of the slide) would be $c a .1 .3 \times 10^{-4}$ the thickness of the KDP standard and hence be $c a .2 .3 \times 10^{3}$ times more effective than KDP for S.H.G. conversion. However, it is possible the patches are of greater thickness and are composed of micro-crystallites formed on the substrate or deposited from micro-crystallites on the subphase. The S.H.G. generated from the material demonstrates that the experimental method has produced non-centrosymmetric material of (4). The coated substrate was tested for S.H.G. activity 6 weeks after deposition and still showed areas of similar strong S.H.G. after 12 weeks when testing ceased. The deposition and monolayer stability tests for (4) were assessed on material of 19:1 acid : methyl ester. Many trials with high purity acid showed the monolayer stability to be unpredictable.

It is interesting that (1) does not form a monolayer while (8) and (9) do so, ${ }^{14}$ and furthermore, multilayers of (9) show a higher degree of structural order than (8). This trend indicates that hydrogen bonding stabilises the monolayer structure.

Preliminary results indicate stilbene systems of a type analogous to (4) are worth investigation because a long carbon chain to stabilise the monolayer is now unnecessary.

Received, 11th November 1987; Com. 1645

\section{References}

1 J. Zyss, J. Mol. Electronics, 1985, 1, 25.

2 D. J. Williams, Angew. Chem., Int. Ed. Engl., 1984, 23, 690.

3 C. Fouquey, J.-M. Lehn, and J. Malhete, J. Chem. Soc., Chem. Commun., 1987, 1424.

4 J. F. Nicond and R. J. Twieg, 'Nonlinear Optical Properties of Organic Molecules and Crystals,' eds. D. S. Chemla and J. Zyss, Academic Press, 1987, vol. 1, p. 277.

5 T. Hurihara, H. Tabei, and T. Kaino, J. Chem. Soc., Chem. Commun., 1987, 959.

6 J. L. Oudar, J. Chem. Phys., 1977, 67, 446

7 I. R. Girling, N. A. Cade, P. V. Kolinsky, J. D. Earls, G. H. Cross, and I. R. Peterson, Thin Solid Films, 1985, 132, 101.

8 D. B. Neal, M. C. Petty, G. G. Roberts, M. M. Ahmad, and W. J. Feast, Electronic Letters, 1986, 22, 460.

9 M. M. Ahmad, W. J. Feast, D. B. Neal, M. C. Petty, and G. G. Roberts, J. Mol. Electronics, 1986, 2, 129.

10 D. B. Neal, M. C. Petty, G. G. Roberts, M. M. Ahmad, W. J. Feast, I. R. Girling, N. A. Cade, P. V. Kolinsky, and I. R. Peterson, Proc. 6th I.E.E.E. Int. Symp., 1986, 87.

11 L. M. Blinov, N. N. Davydova, V. V. Lazorev, and S. G. Yudin, Sov. Phys. Solid State, 1982, 24, 1523.

12 W. S. Wadsworth and W. D. Emmons, J. Am. Chem. Soc., 1961, 83, 1733.

13 M.-R. de Maheas, Bull. Soc. Chim. Fr., 1962, 1989.

14 D. B. Neal, G. J. Russell, M. C. Petty, G. G. Roberts, M. M. Ahmad, and W. J. Feast, J. Mol. Electronics, 1986. 2, 135 